\title{
PATTERN OF PRECIPITATING CAUSES OF DIABETIC KETOACIDOSIS IN A TERTIARY CARE HOSPITAL OF BANGLADESH
}

\author{
MUHAMMAD ABDUR RAHIM ${ }^{1}$, ROZANA ROUF ${ }^{2}$, ASHRAF UDDIN AHMED ${ }^{3}$, KHWAJA NAZIM UDDIN ${ }^{4}$, \\ ZAFAR AHMED LATIF²
}

\begin{abstract}
Background: Diabetic ketoacidosis (DKA) is an established presenting feature of type 1 diabetes mellitus, but infection and non-compliance to anti-diabetic treatment remain the major precipitating causes of DKA among diagnosed diabetic patients. This study was designed to evaluate the precipitating causes of DKA occurring among adult patients.

Methods: This cross-sectional study was done in Bangladesh Institute of Research and Rehabilitation in Diabetes, Endocrine and Metabolic Disorders (BIRDEM) General Hospital, Dhaka, Bangladesh from 2008 to 2011. Diagnosed adult DKA cases were consecutively and purposively included in this study. Patients were evaluated clinically and by laboratory tests aiming at identification of precipitating causes along with management.

Results: Total patients were 200 with slight female (56\%) predominance. Mean age of the study subjects was $37.6 \pm 7.5$ years. Incidence of DKA was more in known diabetic patients (71\%), more among rural population (53\%) and low income group (76.5\%). Infection (45.5\%) was the commonest precipitating cause followed by non-adherence to anti-diabetic therapy (31\%). Acute pancreatitis (5\%), acute myocardial infarction (2\%), stroke (1\%) and surgery (1.5\%) were less common causes and etiology could not be identified in $14 \%$ cases. Severe acidosis $(\mathrm{pH}<7)$ was less common $(8.5 \%)$. Neutrophil leukocytosis was present in $87 \%$ cases. Mortality was $6.5 \%$.

Conclusion: Over two-thirds of DKA cases were precipitated by infection and non-compliance to anti-diabetic treatment in this study. In a significant number of cases, no cause could be identified. Acute pancreatitis appeared as an important cause of DKA in this study.
\end{abstract}

Key words: aetiology, diabetic ketoacidosis, precipitating causes.

Received: 05 June 2017

Accepted: 28 November 2017

DOI: http://dx.doi.org/10.3329/bjmed.v29i1.35401

\section{Introduction}

Diabetic ketoacidosis (DKA) is one themost common and serious hyperglycemic emergencies among patients with diabetes mellitus (DM). Most of the type 1 diabetic patients first present with $\mathrm{DKA}^{1}$, but DKA commonly complicate previously diagnosed diabetic patients of any type,especially if they get infection or become non-compliant to insulin treatment. ${ }^{2-4}$ In a significant number of cases no cause might be identified. ${ }^{4}$ Tissue necrosis like stroke, acute myocardial infarction and acute pancreatitis may precipitate DKA. ${ }^{4,5}$ Treatment of DKA is aimed to correct dehydration, hyperglycemia, electrolyte imbalance and infection, if present.

1. Department of Nephrology, BIRDEM General Hospital and Ibrahim Medical College, Dhaka, Bangladesh;

2. Department of Endocrinology, BIRDEM General Hospital, Dhaka, Bangladesh;

3. Department of Emergency, BIRDEM General Hospital, Dhaka, Bangladesh;

4. Department of Internal Medicine, BIRDEM General Hospital and Ibrahim Medical College, Dhaka, Bangladesh.

Address of Correspondence: Dr. Muhammad Abdur Rahim, Assistant Professor, Department of Nephrology, BIRDEM General Hospital and Ibrahim Medical College,122, Kazi Nazrul Islam Avenue, Dhaka, Bangladesh. Email: muradrahim23@yahoo.com

Bangladesh J Medicine 2018; $29: 3-6$ 
Outcome depends on rapidity of diagnosis andinitiation of appropriate treatment, severity of the disease, age of the patient, identification of precipitating factor and its treatment, presence of co-morbidities and organ dysfunction. ${ }^{6-8}$ This study was designed to evaluate the precipitating causes of DKA among adult patients in a tertiary carehospital of Bangladesh.

\section{Methods}

This cross-sectional study was done in the Department of Internal Medicine, Department of Endocrinology and Department of Critical Care Medicineof Bangladesh Institute of Research and Rehabilitation in Diabetes, Endocrine and Metabolic Disorders (BIRDEM) General Hospital, Dhaka, Bangladesh from 2008 to 2011. Hospitalized adult patients (e"18 years) with a clinical diagnosis of DKA primarily constituted the study population. Diagnosis of DKA and classification was done by using American Diabetic Association (ADA) criteria ${ }^{9}$; mild DKA: an arterial $p \mathrm{H}$ of 7.25-7.30, moderate DKA: arterial $p \mathrm{H}$ 7.0-7.24 and severe DKA: arterial $p \mathrm{H}<7.0$. Patients with ketonuria and high blood glucose with normal arterial $p \mathrm{H}$ were excluded from the study. Patients were evaluated clinically and common investigations including random blood glucose, glycated haemoglobin (HbA1c) (HbA1c < $7 \%$ indicates good glycaemic control and $\mathrm{HbA} 1 \mathrm{c} 7 \%$ or more indicates poor glycaemic control), urine for ketone body, arterial blood gas analysis, complete blood count, serum electrolytes, urea, creatinine, urine routine and microscopic examinations were done for all patients. Culture of appropriate samples and imaging were done as guided by clinical presentation, physical examination findings and reports of initial and routine investigations. All the data including sociodemographic characteristics (including monthly income; low income group $<6000$ taka, lower-middle $6000-<10,000$ taka, middle 10,000-30,000 taka and high $>30000$ taka), clinical presentations, physical findings, laboratory parameters, treatment and outcome were recorded in semi-structured case record forms. Data were analyzed by statistical package for social sciences (SPSS) version 12.0 and results were presented in tables.

\section{Results}

Total number of patients was 200 including 88 males. DKA occurred mostly in diagnosed diabetic patients $(142,71 \%)$ than in new cases $(58,29 \%)$. Base-line characteristics of the study participants are presented in Table I.
Table I

Base-line characteristics of the study population $(N=200)$

\begin{tabular}{lc}
\hline Characteristics & Results \\
\hline Mean age (years) & $37.6 \pm 7.5$ \\
Male: Female & $1: 1.3$ \\
Known DM: New diagnosis of DM & $2.4: 1$ \\
Rural: Urban & $1.1: 1$ \\
Mean RBG at admission (m.mol/L) & $27.1 \pm 7.5$ \\
Mean HbA1c (\%) & $11.3 \pm 3.7$ \\
Severe acidosis $(\mathrm{pH}<7)$ & $8.5 \%$ \\
\hline
\end{tabular}

Note: $\mathrm{DM}=$ diabetes mellitus, $\mathrm{RBG}=$ random blood glucose

DKA occurred mostly among low income group (monthly income <6000 Bangladeshi taka, 76.5\%) and patients with poor glycemic control (HbA1c $>7 \%$ in 94\%). Regarding anti-diabetic management of diagnosed diabetic patients, 88 patients were on insulin, 23 on oral anti-diabetic agents (OAD), 28 on both insulin and OAD and 3 patients were on medical nutrition therapy (MNT) only. Mild (72, 36\%) to moderate $(111,55.5 \%)$ DKA were more common than severe $(17,8.5 \%)$ DKA.Common presentations are shown in Table II.

Table II

Clinical presentations of the study populations $(N=200)$

\begin{tabular}{lc}
\hline Features & Frequency (Percentage) \\
\hline Nausea & $126(63)$ \\
Vomiting & $122(61)$ \\
Polyuria & $86(43)$ \\
Polydipsia & $85(42.5)$ \\
Fever & $58(29)$ \\
Abdominal pain & $56(28)$ \\
Shortness of breath & $56(28)$ \\
Blurred vision & $26(13)$ \\
Coma & $14(7)$ \\
\hline
\end{tabular}

Note: All patients had more than one symptoms

Infection $(91,45.5 \%)$ was the most common precipitating cause of DKA, both in previously diagnosed diabetic patients and new cases. Other causes are presented in Table III. 
Table III

Precipitating causes of DKA among the study participants $(N=200)$

\begin{tabular}{lccc}
\hline Causes & Total (200) & Diagnosed DM (142) & New (58) \\
\hline Infection & 91 & 51 & 40 \\
UTI & 67 & 39 & 28 \\
Pneumonia & 11 & 5 & 6 \\
Pulmonary tuberculosis & 6 & 3 & 3 \\
Diabetic foot ulcer & 4 & 3 & 1 \\
Liver abscess & 3 & 1 & 2 \\
Non-compliance & 62 & 62 & --- \\
Insulin omission & 49 & 49 & --- \\
Non-judicious reduction of dose & 13 & 13 & --- \\
Acute pancreatitis & 10 & 2 & 8 \\
Acute myocardial infarction & 4 & 3 & 1 \\
Surgery & 3 & 3 & 0 \\
Stroke & 2 & 2 & 0 \\
Unidentified & 28 & 19 & 9 \\
\hline
\end{tabular}

Neutrophil leukocytosis was present in $87 \%$ cases, irrespective of presence of infection. Gross electrolyte imbalance at admission was less common but $97 \%$ patients required potassium infusion during the hospital course. Overall mortality was $6.5 \%$, more among patients with acute pancreatitis $(6 / 10,60 \%)$.

\section{Discussion}

This study was designed to evaluate the precipitating causes of DKA in a tertiary care setting of a developing country. We found that DKA occurred mostly in known diabetic patients, more in females and low incomegroup, which is consistent with two previous reports from Bangladesh. ${ }^{4,5}$ In two different reports from Kenya ${ }^{10}$ and Taiwan ${ }^{11}$ almost similar picture is seen. Poverty and gender discriminations may contribute in availability of care for medical needs for chronic diseases like diabetes in developing countries like that of Bangladesh, which might be a contributory factor for such socio-demographic pattern of DKA cases.

In this study, DKA occurred mostly among previously diagnosed diabetic patients. This scenario is common in local studies ${ }^{4,5,12}$ as well as in international reports. ${ }^{13,14}$

Precipitating causes of DKA were not different in this study from previous studies in Bangladesh. ${ }^{4,5,12}$ Infection and non-compliance to anti-diabetic medications were common precipitants in the current study accounting for over three-fourth of cases. Almost similar picture was seen in different studies throughout the world. ${ }^{13-18}$ Jabbar A et al. ${ }^{19}$ found that in twothird of type 2 diabetic patients, DKA was precipitated by infection and after recovery from DKA; many of them were on OADs without recurrence of DKA. This observation explains that infection can unmask previously undiagnosed type 2 diabetic patients, as reported by Pinto $\mathrm{ME}$ et al. ${ }^{17}$ In different studies it was found that, in up to $25 \%$ of patients with DKA precipitating cause could not be identified. ${ }^{4,17}$

Outcome of this study showed that $6.5 \%$ patients expired in hospital. Almost similar results were found in two different reports from Bangladesh. ${ }^{4,5}$ Outcome of DKA is variable, depends upon time of diagnosis and onset of treatment, underlying causes and standards of care. ${ }^{9}$ Mortality was $14 \%$ in $\mathrm{UK}^{20}, 11.8 \%$ in Korea $^{8}$ and $29.8 \%$ in Kenya. ${ }^{10}$ With better understanding of the pathophysiology of DKA and improvements in treatment, outcome is improving.

Failure to classify patients as having type 1 or type 2 diabetes, especially those who were not previously diagnosed as diabetic, was an important limitation of the current study. Few of the study subjects had fibro-calcific-pancreatic-diabetes (FCPD) as well.

\section{Conclusions}

From the current study, it can be concluded that, DKA occurred mostly among known diabetic patients. Common precipitating causes were infection and nonadherence to anti-diabetic treatment. Failure to 
identification of precipitant was not uncommon. Proper patient education regarding importance of treatment adherence and diabetic management during an inter-current infectioncan prevent many episodes of DKA and thus can reduce morbidity and mortality of diabetic patients.

Conflict of interest: Nothing to declare.

\section{References}

1. Onyiriuka AN, Ifebi E. Ketoscidosis at diagnosis of type 1 diabetes in children and adolescents: frequency and clinical characteristics. J Diabetes MetabDisord. 2013; 12: 47.

2. Tan H, Zhou Y, Yu Y. Characteristics of diabetic ketoacidosis in Chinese adults and adoloscents - a teaching hospital-based analysis. Diabetes Res ClinPract. 2012;97(2):306-312.

3. Al-Rubeaan KA, Aftab SA, Alotaibi MS, Alghamdi AA, Rafiullah MR. Clinico-laboratory characteristics of diabetic ketoacidosis in adults in tertiary hospital in Saudi Arabia. Ur Rev Med Pharmacol Sci. 2011;15(10):1202-1206.

4. Rahim MA, Uddin KN, Zaman S, Musa AKM, Rahman MR, Hossain MD et al. Clinical spectrum and management of diabetic ketoacidosis: experience in a tertiary care hospital. Birdem Med J. 2011;1(1):1520.

5. Ahmed AU, Rahim MA, Rahman MR, Nazim RF, Uddin KN. Diabetic Ketoacidosis: Pattern of Precipitating Causes. J Enam Med Col. 2014; 4(2): 94-97.

6. Hardern RD, Quinn ND. Emergency management of diabetic ketoacidosis in adults. Emer Med J. 2003;20(3);210-213.

7. Henriksen OM, Prahl JB, Roder ME, Svendsen OL. Treatment of diabetic ketoacidosis in adults in Denmark: a national survey. Diabetes Res ClinPract. 2007;77(1):113-119.

8. Ko SH, Lee WY, Lee JH, Kwon HS, Lee JM, Kim SR et al. Clinical characteristics of diabetic ketoacidosis in Korea over the past two decades. Diabet Med. 2005;22(4):466-469.

9. KitabchiAE, Umpierrez GE, Miles JM, Fisher JN. Hyperglycaemic crises in adult patients with diabetes. Diabetes Care. 2009;32(7):1335-1343.
10. Mbugua PK, Otieno CF, Kayima JK, Amayo AA, McLigeyo SO. Diabetic ketoacidosis: clinical presentation and precipitating factors at Kenyatta National Hospital, Nairobi. East Afr Med J. 2005;82 (12 supl):s191-196.

11. Lin SF, Lin JD, Huang YY. Diabetic ketoacidosis: comparisons of patient characteristics, clinical presentations and outcomes today and 20 years ago. Chang Gunh Med J. 2005;28 (1):24-30.

12. Hossain MZ, Muhammad A, Azad KAK, Deb SR, Rahman MM, Anwar ASMT et al. Clinical characteristics of diabetic ketoacidosis in type 2 diabetes mellitus in Bangladeshi adult patients. $\mathrm{J}$ Dhaka Med Coll. 2012;21(2):131-139.

13. Xu Y, Bai J, Wang G, Zhong S, Su X, Huang $Z$ et al. Clinical profile of diabetic ketoacidosis in tertiary hospitals in China: a multicentre, clinic-based study. Diabet Med. 2016;33(2):261-268.

14. Naeem MA, Al-Alem HA, Al-Dubayee MS, Al-Juraibah FN, Omair A, Al-Ruwaili AS et al. Characteristics of pediatric diabetic ketoacidosis patients in Saudi Arabia. Saudi Med J. 2015;36(1):20-25.

15. Musey VC, Lee JK, Crawford R, Klatka MA, McAdams D, Phillips LS. Diabetes in Urban AfricanAmericans. I. Cessation of Insulin Therapy Is the Major Precipitating Cause of Diabetic Ketoacidosis. Diabetes Care. 1995; 18(4): 483-489.

16. Weinert LS, Scheffel RS, Severo MD, Cioffi AP, Teló $\mathrm{GH}$, Boschi A et al. Precipitating factors of diabetic ketoacidosis at a public hospital in a middle-income country. Diabetes Res ClinPract. 2012;96(1):29-34.

17. Pinto ME, Villena JE, Villena AE. Diabetic ketoacidosis in Peruvian patients with type 2 diabetes mellitus. EndocrPract. 2008;14(4):442-446.

18. Alourfi $Z$, Homsi H. Precipitating factors, outcomes, and recurrence of diabetic ketoacidosis at a university hospital in Damascus. Avicenna J Med. 2015; 5(1):11-15.

19. Jabbar A, Farooqui K, Habib A, Islam N, Haque N, Akhter J. Clinical characteristics and outcome of diabetic ketoacidosis in Pakistani adults with type 2 diabetes mellitus. Diabet Med. 2004;21(8):920923.

20. Sharma V, Hadebe N. Diabetic ketoacidosis: principles of management. Br J Hosp Med (Lond). 2007;68(4):184-189. 